Fisheries 1986, v.11, n.3, pp.2-6

ISSN: $1548-8446$

DOI: 10.1577/1548-8446(1986)011<0002:CFORAC>2.0.CO;2

http://afs.allenpress.com/perlserv/?request=get-archive

http://afs.allenpress.com/archive/1548-8446/11/3/pdf/i1548-8446-11-3-2.pdf

(C) Copyright by the American Fisheries Society 1986 


\title{
Competition for Open-Access Resources: A Class Exercise that Demonstrates the Tragedy of the Commons
}

\author{
Barry L. Johnson and Roy A. Stein
}

\begin{abstract}
Open-access resources, such as fisheries, often suffer from overexploitation due to competition among individuals. To help students appreciate this phenomenon, we developed a laboratory exercise that uses a computer model of a commercial fishery to illustrate the inevitability of overexploiting open-access resources. Our model contained two identical populations that were fished simultaneously: one on an individual, competitive basis and the other on a collective, cooperative basis. Both populations were governed by identical relationships for recruitment and catch-per-effort, and had constant growth and natural mortality rates. Competition within the individually-run fishery invariably led to population collapse whereas the cooperative group usually maintained sustained yields. This exercise demonstrated that optimal resource use was impossible in a purely competitive fishery and helped students understand fish population biology and commercial fishing strategies. The exercise can show how changes in regulations or population parameters influence yields from a fishery. It can be adapted for use in workshops and other professional settings, even for participants with little background in fisheries.
\end{abstract}

$\mathbf{M}$ any of the world's important resources, from wilderness areas to fisheries to parking spaces, are publicly owned, and thus are considered common property resources. Most common property resources are also open-access resources, meaning they are available to all who desire to use them. Such unrestricted access often results in excessive levels of use and, ultimately, overexploitation or ruin of the resource. Hardin (1968) has termed this process, the "tragedy of the commons." The tragedy results from the economics of exploiting a common resource. Use of any resource involves a positive and negative component for the user. The positive component (utility in an economic sense) is a benefit derived from the resource and accrues entirely to the user. The negative component is the cost of damage done to the resource as a result of use. With a common resource, this cost is not borne entirely by the individual, but is shared by all resource users. For any individual, the benefit is almost always larger than his share of the cost; thus it is advantageous for the individual to increase use of the resource. However, because this reasoning applies to all, the result is escalating use and, ultimately, overexploitation.

The development of management strategies that allow appropriate use of common property but avoid overexploitation is one of the most pervasive problems in resource management (e.g., Fonda 1971; Hardin and Baden 1977; Clark 1985). However, students often have difficulty developing a practical appreciation for the issues and constraints involved in such complex management problems. To help students appreciate these complexities, we developed a participatory class exercise that demonstrates the "tragedy of the commons." The exercise uses a computer model of a commercial fishery, where students act as harvesters, and helps students gain an understanding of basic fish population biology and some of the problems confronting a commercial harvester or manager. The exercise was designed for upper-level undergraduate and graduate students.

\section{The Model}

The computer model used in the exercise was a single-species, age-structured population model containing two separate but identical fish populations (Fig. 1). Each population consisted of 10 age classes, with ages 2 through 9 susceptible to fishing. The model did not simulate any particular fishery, but was built on generalized relationships. Numbers and weight at age followed typical exponential curves; with these curves, biomass peaked between ages 3 and 4 (Fig. 2). For simplicity, we assumed constant growth and natural mortality. Recruitment to age 2 was governed by a Ricker-type stock/recruit curve with a random component (Fig. 3). At age 2,50\% of the fish matured and by age 3 , all were mature. Populations were fished with gill nets of 2$\mathrm{cm}$ to $9-\mathrm{cm}$ mesh, with $2-\mathrm{cm}$ mesh taking age-2 fish, 3-cm mesh taking age-3 fish, and so on. Catch in each mesh size for each boat was based on an asymptotic catch curve applied to initial numbers in each age class (Fig. 4A). Catchper-effort began to decline when the number in an age class reached $75 \%$ of the initial number for that age class (Fig. 4B). 


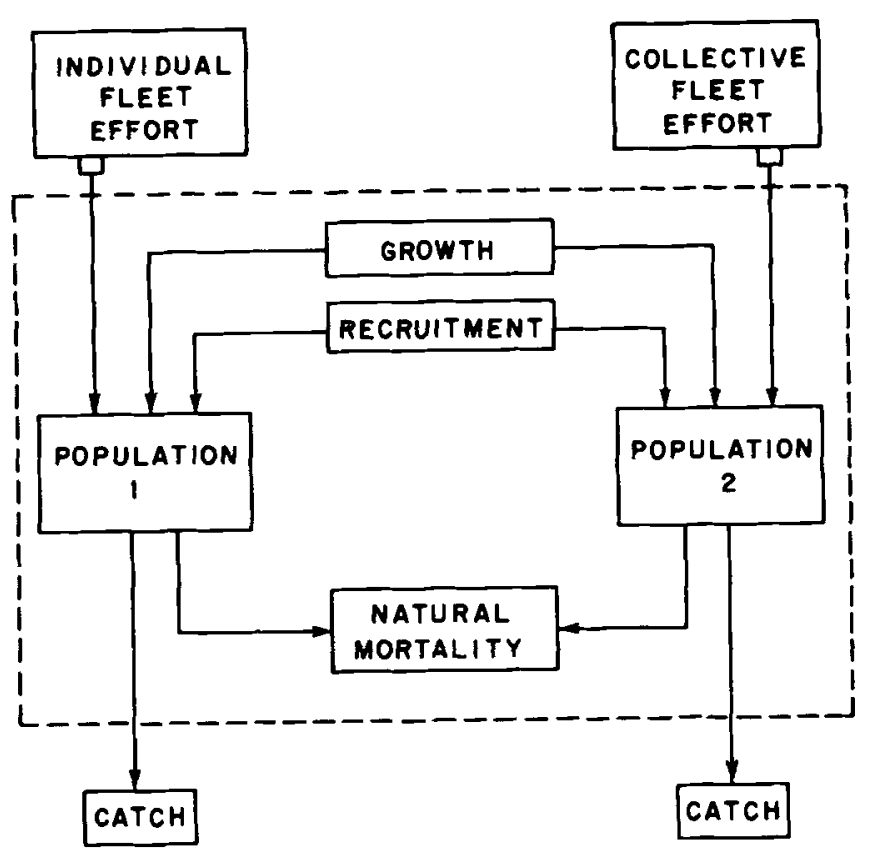

Figure 1. Box diagram of the "tragedy of the commons" laboratory simulation. Boxes within the dotted line represent components of the computer model. The model contains two identical fish populations that are exploited separately by two different fishing fleets. Input to the model is the effort expended by each fleet, and output is the resulting catch for each fleet. Both populations are governed by the mathematical relationships represented in Figs. 2 through 4.

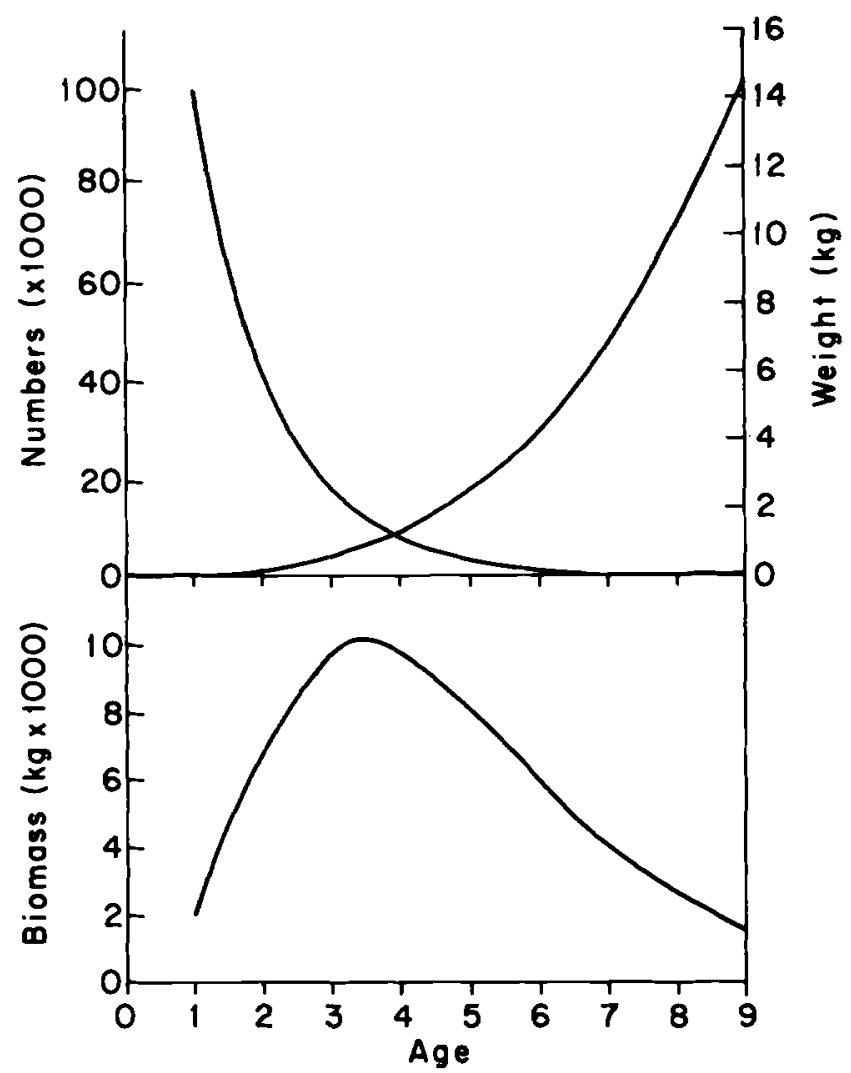

Figure 2. Relations for individual weight at age and initial numbers and biomass in each age class for the commercial fishery model.

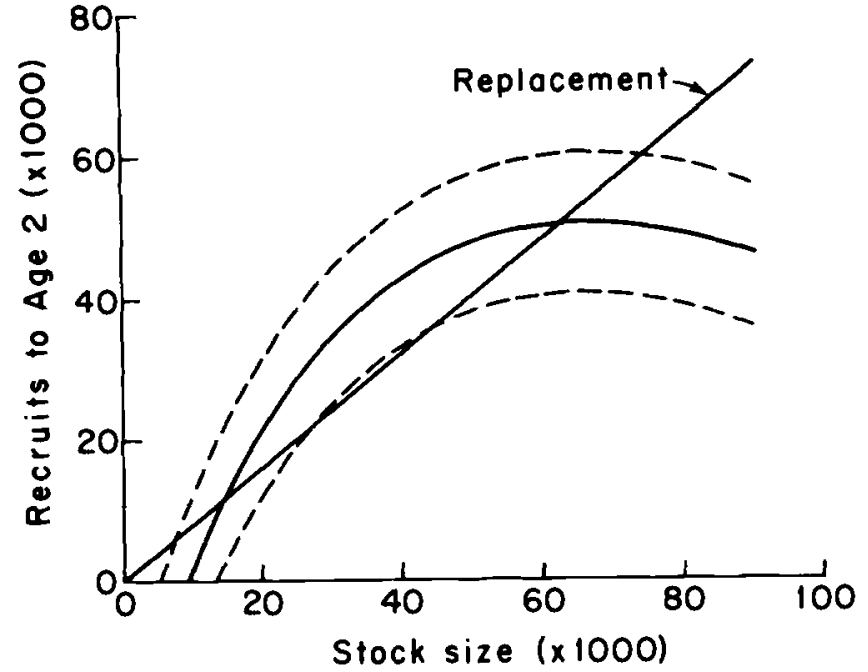

Figure 3. Stock-recruit relation in the commercial fishery computer model. Stock is expressed as total number of mature fish, and recruitment is expressed as year class size at age 2 . The dashed lines represent computer generated random variability (maximum of $+(-10,000)$ around the relation.
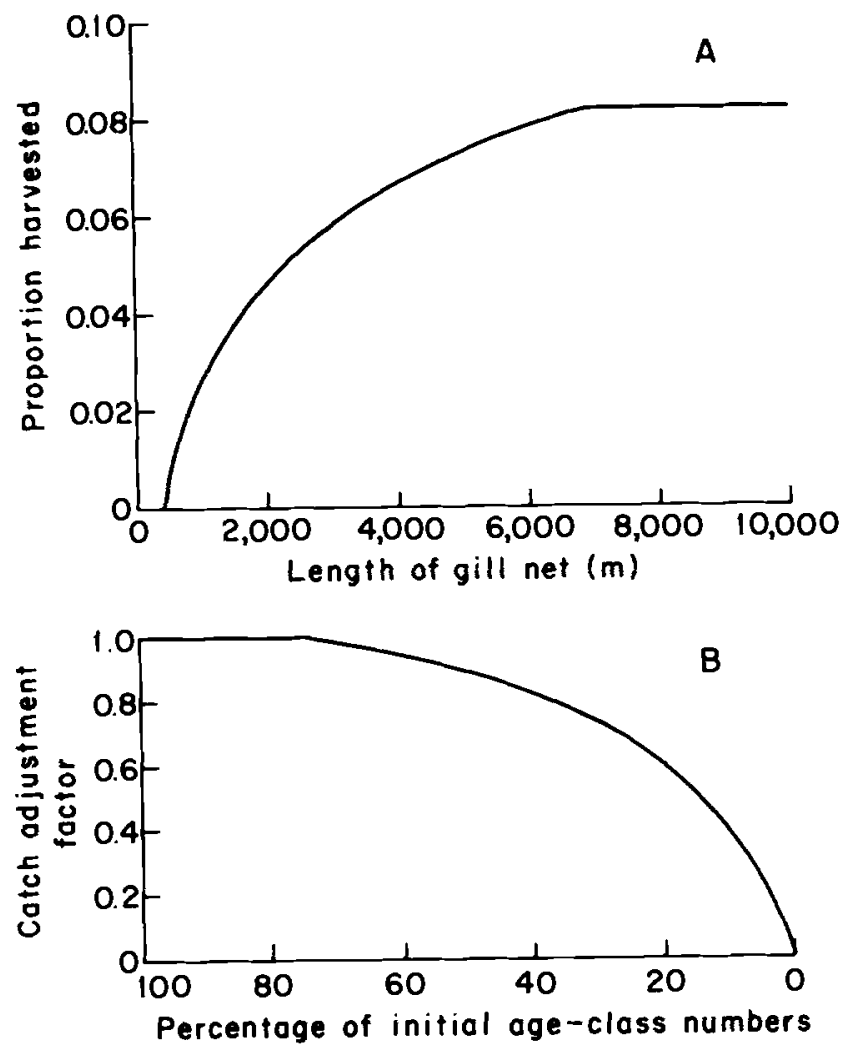

Figure 4. Catch relations in the commercial fishery computer model. (A) Proportion of age class harvested versus length of gill net fished by a single boat in one mesh size. Beyond 7,000 $\mathrm{m}$ the curve is flat. The proportion is applied to initial age class numbers. (B) Catch adjustment factor versus age class size. When numbers in an age class decline to less than $75 \%$ of their initial number, catch is reduced by multiplying by the corresponding adjustment factor. 


\section{The Exercise}

Students were assigned to "boats" that made up two fishing fleets. Most of the class was in the "Individual" fleet where the crew (usually 2-4 people) of each boat determined the mesh size and length of net they would fish. The Individual fleet represented an unrestricted, competitive fishery. The remainder of the class was assigned to the "Collective" fleet. In this fleet, all members collaborated to make a joint decision about mesh size and length of net to fish. All boats were then required to abide by this decision. The Collective fleet represented a restricted, cooperative fishery.

Typically five boats were assigned per fleet. Each boat fished a maximum of $10,000 \mathrm{~m}$ of net, distributed among the eight mesh sizes in 1,000 -m increments. For example, one boat in the Individual fleet (or all boats in the Collective fleet) might fish its $10,000 \mathrm{~m}$ by choosing $1,000 \mathrm{~m}$ of $2-\mathrm{cm}$ mesh, 1,000 $\mathrm{m}$ of $3-\mathrm{cm}, 3,000 \mathrm{~m}$ of $4-\mathrm{cm}, 5,000 \mathrm{~m}$ of $5-\mathrm{cm}$, and none in 6-9-cm mesh (i.e., boat number 3 in Table 1).

The Collective fleet fished one population, while the Individual fleet fished the other population simultaneously. Thus, the dynamics of the two populations could be compared directly over time. Because each fleet fished the same total net effort and functional relationships for both populations were identical, any difference between the two populations over time resulted from a difference in allocation of net effort across mesh sizes.

The model operated in annual increments. At the beginning of each year, each boat decided how to allocate its net effort for that year and reported its strategy to the instructor who entered this information into the computer. The model than calculated annual catch in each age class, for both populations, based on effort expended by each fleet. At year's end, number of mature fish in each age class was computed by subtracting catch from numbers at the beginning of the year. In age class 2, mature fish were caught before immatures, because they were expected to be larger and more vulnerable to the gear. Stock size was then calculated by summing mature fish in each age class and recruitment was determined from the stock/recruit relationship. Numbers in age classes 3-9 for next year were cal- culated by multiplying year-end numbers by survival rate. An annual report of catch and effort was then printed and distributed to each boat (Table 1). These annual cycles continued until one population collapsed; then the exercise was repeated. Generally, about seven annual simulations, or 1.5 hours, were required for a population to collapse.

During the exercise, students were not given any information regarding model operation or parameters. Their only knowledge of the model was the catch that resulted from effort expended. Students were required to analyze annual reports, determine how the model (i.e., fish population) operated, and then use that knowledge to optimize their fishing strategy. The instructor, however, did receive an annual summary of population data including information on stock size, age structure, weather conditions for spawning, and strength of the new yearclass. This information told the instructor how each population was faring and could be used to modify the exercise (see Variations and Possibilities).

To encourage competition among boats, we told students that grades for the laboratory would be assigned based on total weight caught. Annual reports included cumulative weight caught (Table 1) and thus provided a ranking of boats. Because all boats in the Collective fleet had identical catches, they were ranked together, as a single unit, against each boat in the Individual fleet. These rankings were continually updated on the blackboard; high-ranking boats were encouraged and low-ranking boats chastised. Actually, we assigned grades based on a laboratory report, but the ruse worked well to generate competition. Usually our bluff was called by the third run of the exercise. Even then, student enthusiasm remained high and competition was strong.

\section{The Outcome}

Outcomes of the exercise over suc-

Table 1. Sample annual report produced by the commercial fishery computer model. Each report includes gill net effort and catch (both numbers and weight) in each mesh size, for each boat, plus total annual and cumulative weight caught for each boat. The Collective fleet is represented by a single boat because all fleet members are required to fish identically.

\begin{tabular}{|c|c|c|c|c|c|c|c|c|c|c|c|}
\hline \multicolumn{12}{|c|}{ Catch and effort per boat: year 5} \\
\hline & & \multicolumn{8}{|c|}{ Mesh size } & \multirow{2}{*}{$\begin{array}{l}\text { Annual } \\
\text { catch }\end{array}$} & \multirow{2}{*}{$\begin{array}{c}\text { Cumulative } \\
\text { catch }\end{array}$} \\
\hline \multicolumn{2}{|c|}{ Boat number } & \multicolumn{2}{|c|}{$2 \mathrm{~cm} 3 \mathrm{~cm}$} & \multicolumn{6}{|c|}{$4 \mathrm{~cm} 5 \mathrm{~cm} 6 \mathrm{~cm} 7 \mathrm{~cm} 8 \mathrm{~cm} 9 \mathrm{~cm}$} & & \\
\hline \multicolumn{12}{|c|}{ COLLECTIVE FLEET } \\
\hline Per & Effort(m) & & 1000 & 3000 & 4000 & 2000 & 0 & 0 & 0 & & \\
\hline boa & Catch(\#) & 0 & 473 & 446 & 209 & 30 & 0 & 0 & 0 & & \\
\hline & Weight(kg) & 0 & 255 & 571 & 523 & 128 & 0 & 0 & 0 & 1477 & 7382 \\
\hline \multirow{4}{*}{1} & \multicolumn{11}{|c|}{ INDIVIDUAL FLEET } \\
\hline & Effort(m) & 2000 & 2000 & 2000 & 2000 & 2000 & 0 & 0 & 0 & & \\
\hline & Catch(\#) & 1209 & 380 & 239 & 93 & 38 & 0 & 0 & 0 & & \\
\hline & Weight(kg) & 193 & 205 & 307 & 232 & 164 & 0 & 0 & 0 & 1101 & 7415 \\
\hline \multirow[t]{3}{*}{2} & Effort(m) & 5000 & 1000 & 1000 & 1000 & 1000 & 1000 & 0 & 0 & & \\
\hline & Catch(\#) & 1904 & 215 & 135 & 52 & 21 & 12 & 0 & 0 & & \\
\hline & Weight(kg) & 305 & 116 & 173 & 131 & 93 & 79 & 0 & 0 & 897 & 6960 \\
\hline \multirow[t]{3}{*}{3} & Effort(m) & 1000 & 1000 & 3000 & 5000 & 0 & 0 & 0 & 0 & & \\
\hline & Catch(\#) & 683 & 215 & 300 & 146 & 0 & 0 & 0 & 0 & & \\
\hline & Weight(kg) & 109 & 116 & 384 & 365 & 0 & 0 & 0 & 0 & 975 & 7118 \\
\hline \multirow[t]{3}{*}{4} & Effort(m) & 3000 & 3000 & 3000 & 1000 & 0 & 0 & 0 & 0 & & \\
\hline & Catch(\#) & 1517 & 477 & 300 & 52 & 0 & 0 & 0 & 0 & & \\
\hline & Weight(kg) & 243 & 258 & 384 & 131 & 0 & 0 & 0 & 0 & 1016 & 7357 \\
\hline \multirow[t]{3}{*}{5} & Effort(m) & 0 & 0 & 0 & 0 & 4000 & 4000 & 3000 & 0 & & \\
\hline & Catch(\#) & 0 & 0 & 0 & 0 & 54 & 26 & 12 & 0 & & \\
\hline & Weight(kg) & 0 & 0 & 0 & 0 & 235 & 176 & 127 & 0 & 538 & 6081 \\
\hline
\end{tabular}


cessive runs yielded consistent results. The first run was basically a trial run where students learned how the fishery operated and began developing fishing strategies. Usually both populations collapsed during the first run. In the second run, some students approached the maximum-catch strategy. This was most easily accomplished by using the catch and effort data for all boats to create a marginal yield table (Table 2). Marginal yield is defined as the catch that results from the last increment of effort; here, 1,000 m of net. For example, in 5-cm mesh, 2,000 $\mathrm{m}$ of net catches $378 \mathrm{~kg}$ and $3,000 \mathrm{~m}$ catches $474 \mathrm{~kg}$. Thus, at $3,000 \mathrm{~m}$, the catch which resulted from the last $1,000 \mathrm{~m}$ of net was $474 \mathrm{~kg}-378 \mathrm{~kg}=96 \mathrm{~kg}$. Once the marginal yield table was created, maximum-catch strategy was determined by allocating the $10,000 \mathrm{~m}$ of net to the combinations of effort and mesh size that produced the highest total return (Table 2). Marginal yields, and thus maximum-catch strategy, changed as numbers in each age class changed. But, the predicted yields in Table 2 were usually accurate for the first 3 to 4 years. Other methods used by students to improve their fishing strategies included calculating catch-per-effort or, for less sophisticated students, merely copying the strategies of more successful boats. Depending upon the analytical skills of the group, we would sometimes provide guidance in analyzing data. During the second run, the Individual fleet crashed their population, whereas the Collective fleet usually produced a sustained yield.

By the third run, competition among boats in the Individual fleet resulted in everyone approaching the maximumcatch strategy. However, this strategy caused overfishing of young age classes,

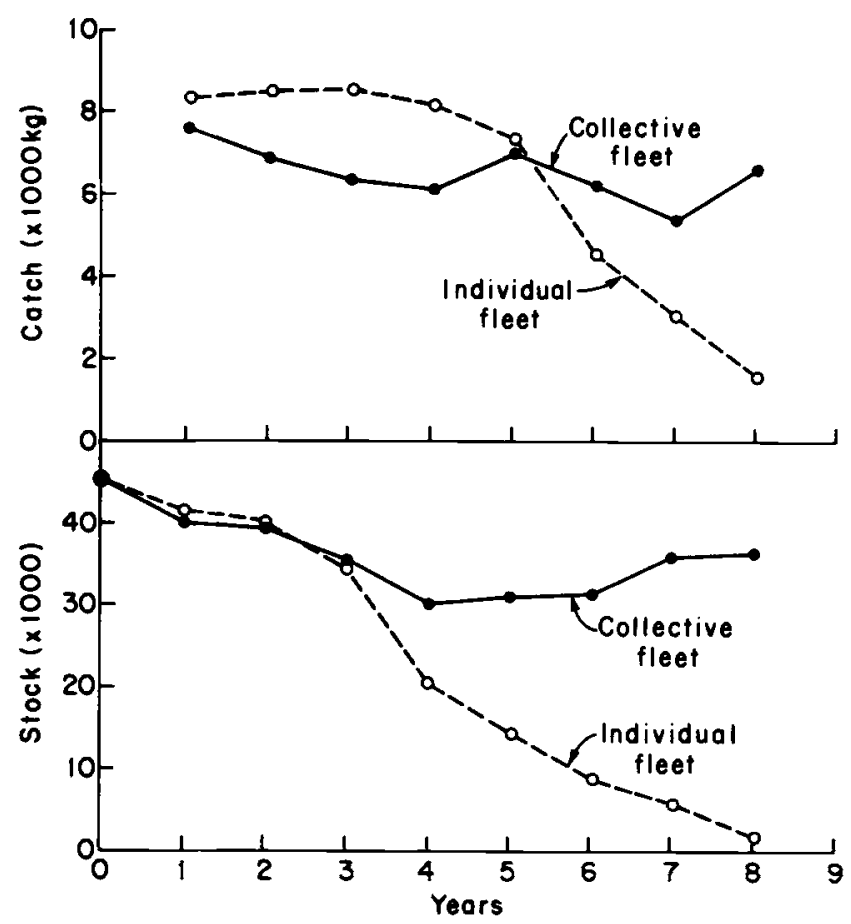

Figure 5. Typical outcome of "the tragedy of the commons" exercise. The Individual fleet has higher catches initially, but at the cost of overfishing and stock collapse. The Collective fleet can produce sustained yield. reductions in stock, and ultimately, recruitment failure. In contrast, the Collective fleet, with its knowledge of population biology, avoided fishing the younger age classes, thus maintaining stock and producing sustained yields (Fig. 5). Therefore, the Collective fleet ranked low in weight caught initially, but surpassed all boats in the Individual fleet within a few years. By the third run, students in the Individual fleet realized that they could not catch more than the Collective fleet, and that they must try to produce sustained yields. Thus, they began to cooperate to re-
Table 2. Marginal yield of 1,000-m gill net increments for mesh sizes two through seven, before depletion of any age classes, in the commercial fishery computer model. Underlined values represent the 10 highest marginal yields and define the maximum-catch strategy for $10,000 \mathrm{~m}$ of net, i.e., $2000 \mathrm{~m}$ in $2-\mathrm{cm}$ through $6-\mathrm{cm}$ mesh. See text for how to calculate marginal yields.

\begin{tabular}{|c|c|c|c|c|c|c|}
\hline \multirow[b]{2}{*}{$\begin{array}{l}\text { Total } \\
\text { effort }\end{array}$} & \multicolumn{6}{|c|}{ Kilograms per marginal $1,000 \mathrm{~m}$ of gill net } \\
\hline & $\begin{array}{l}2-\mathrm{cm} \\
\text { mesh }\end{array}$ & $\begin{array}{l}3-\mathrm{cm} \\
\text { mesh }\end{array}$ & $\begin{array}{l}4-\mathrm{cm} \\
\text { mesh }\end{array}$ & $\begin{array}{l}5-\mathrm{cm} \\
\text { mesh }\end{array}$ & $\begin{array}{l}\text { 6-cm } \\
\text { mesh }\end{array}$ & $\begin{array}{l}7-\mathrm{cm} \\
\text { mesh }\end{array}$ \\
\hline 1,000 & 178 & 256 & 257 & 214 & 157 & 106 \\
\hline 2,000 & $\overline{137}$ & $\overline{197}$ & $\overline{198}$ & $\overline{164}$ & $\overline{121}$ & 81 \\
\hline 3,000 & $\overline{81}$ & $\overline{115}$ & $\overline{116}$ & $\overline{96}$ & $\overline{71}$ & 48 \\
\hline 4,000 & 56 & 82 & 82 & 68 & 50 & 34 \\
\hline
\end{tabular}

duce harvest of young age classes and conserve stock.

Sustained yields for the Individual fleet resulted in more fish for all boats in the long run. However, these boats were still ranked individually, with points awarded accordingly. Thus, there was much incentive for low-ranking boats to improve their position. By the third run, everyone was well aware of how the fishery operated, and fishing strategies were similar. This resulted in weight totals being fairly close, but also made it difficult for boats to improve their rank. The easiest way to increase catch was to dissent from the cooperative strategy, either overtly or covertly (by cheating). Fishing a few thousand meters of small mesh net produced catches large enough to improve a boat's rank significantly. Because cooperation was not required, dissension often occurred. If one boat dissented, it moved up quickly in rank, displacing other boats downward. This strategy was doubly effective, because by catching young fish, the dissenters also reduced the future catch in older age classes by other fleet members. In order for the remaining fleet members to improve or maintain their rank, they were forced 
to fish smaller mesh sizes also, thus destroying the cooperative strategy. Conservation efforts by only a few fleet members were ineffective because any young fish they did not catch were caught by the dissenters. Although the ultimate result of the third run varied depending on the ability of the individual fleet to coerce members to cooperate, all outcomes demonstrated the essence of the "tragedy of the commons": that optimal use of the resource was impossible in an unrestricted, purely competitive fishery.

We have used the exercise in graduate seminars, and as the focus of a laboratory in fishery biology courses at the Ohio State University, University of Vermont, and University of Wisconsin-Madison. The exercise always generated a great deal of enthusiasm in participants. Student evaluations of the laboratory were quite positive; nearly all felt the exercise was a useful, realistic learning tool.

\section{Variations and Possibilities}

The exercise can be expanded to show how changes in population structure will affect fishing strategy or to evaluate the effects of regulations on the fishery. Regulating effort does not require any changes in the computer program but can be effected merely by imposing restrictions on harvesters. Such restrictions might include a minimum mesh size regulation or allowing less effort per boat. A student "management agency" might institute regulations. Another possibility would be to report the weather and year-class strength indices to students. They could use these indices to fine tune their strategies annually, or as a warning of possible population collapse. Also, the computer program allows the instructor to input the random component for the stock/ recruit relation in each year. This could be used to guide population dynamics, or to simulate a particular sequence of good or poor years. Changes in parameters such as stock/recruitment relation, age at maturity, survival, growth, and catch-per-effort would require changes in the computer program, but would be relatively easy to make. Changes in these parameters could be evaluated singly or in conjunction with various management strategies to determine under what conditions the "tragedy of the commons" might be avoided.

The usefulness of the exercise is not limited to classroom laboratory situations. It could easily be adapted for use with extension groups, management agency workshops, or commercial harvesters. Although participation in the exercise does require some knowledge of fishery biology, we have used the model successfully with groups that have little background in fisheries. This merely required taking a few minutes before beginning the exercise to introduce some basic concepts about population biology and how a gill net fishery operates.

\section{Summary}

The exercise proved to be an effective tool for teaching students about exploitation and management of open-access resources. It allowed students to develop an understanding, through their own actions as harvesters, of the forces producing the "tragedy of the commons." They exhibited many characteristics shown by exploiters of common resources in the real world. The failed efforts of members of the Individual fleet to reduce harvest and conserve stock showed how competition among individuals can subvert well intentioned management plans. Students also saw that individual fishermen are not inherently evil because they participate in overfishing, but may just be caught up in a situation where they have no viable alternative.

The exercise was also a good example of how computer modeling can be used in education. The computer modeling approach allowed us to simulate, in a few hours in the classroom, a situation that would be very difficult for students to experience on their own. Participation in the simulation provided an added dimension of understanding not available through merely reading about or discussing the "tragedy of the commons."

\section{Notes}

A listing of the computer program and user's gujde for the laboratory exercise are available from the first author. The computer model is available in versions for the Apple Ile (programmed in Apple PASCAL) or the Radio Shack TRS 80, Model 4 (programmed in TRS 80 BASIC). Both versions require a disk drive, monitor, and printer. We would be glad to copy the program on a $51 / 4$-inch floppy disk if you will provide a blank disk for that purpose.

\section{Acknowledgments}

We thank B. Menzel and J. Ney for reviewing the manuscript. This work was supported in part by the Ohio State University, Department of Zoology, and by the University of Wisconsin Sea Grant Institute under grants from the $\mathrm{Na}$ tional Sea Grant College Program, National Oceanic and Atmospheric Administration, U.S. Department of Commerce, and from the State of Wisconsin. Federal grant NA84AA-D-00065, project R/GB-24.

\section{References}

Clark, C. W. 1985. Bioeconomic modeling and fisheries management. John Wiley and Sons, New York, NY.

Fonda, R. W. 1971. The Puget Sound sulphite pulp mills and the tragedy of the commons. Biological Conservation 4:3138 .

Hardin, G. 1968. The tragedy of the commons. Science 162:1243-1248.

Hardin, G., and J. Baden, eds. 1977. Managing the commons. W. H. Freeman, San Francisco, CA. 